Regular Articles

\title{
Prevalence of Intestinal Endoparasites With Zoonotic Potential in Domestic Cats From Botucatu, SP, Brazil
}

\author{
Fúlvia Bueno de Souza, DVM ${ }^{a}$, Isabela Maciel Nakiri, DVM ${ }^{\mathrm{a}}$, \\ Natália de Oliveira Lourenço, DVM ${ }^{\mathrm{a}}$, Gustavo Gomes da Silva, DVM ${ }^{\mathrm{a}}$, \\ Débora Rizzo Paschoalini ${ }^{\mathrm{a}}$, Priscylla Tatiana Chalfun Guimarães-Okamoto, $\mathrm{PhD}^{\mathrm{b}}$, \\ Alessandra Melchert, $\mathrm{PhD}^{\mathrm{b}, *}$
}

Keywords:

copro-parasitological examination

feline

parasitosis

Brazil

${ }^{a}$ School of Veterinary Medicine and Animal Science, Universidade Estadual Paulista (UNESP), Botucatu, SP, Brazil

${ }^{b}$ Department of Veterinary Clinic, School of Veterinary Medicine and Animal Science, Universidade Estadual Paulista (UNESP), Botucatu, SP, Brazil

*Address reprint requests to: Alessandra Melchert, PhD, Department of Veterinary Clinic, School of Veterinary Medicine and Animal Science, Universidade Estadual Paulista (UNESP), Distrito de Rubião Junior, s/n, 18618-970 Botucatu, SP, Brazil

E-mail: alessandra@fmvz.unesp.br (A. Melchert)
Intestinal endoparasites in cats have received increasing attention worldwide due to the increase in the population of cats and their intimate relationship with people. However, concern about the zoonotic potential of these agents is still small. The aim of this study was evaluating the occurrence of intestinal endoparasites, the most prevalent ones, as well as the profile of affected cats. We conducted a survey of the medical records of cats treated at Small Animal Medical Clinic, in the Veterinary Hospital of the University of Veterinary Medicine and Animal Sciences-campus Botucatu, São Paulo, Brazil. Medical records between January 2011 and September 2015 were evaluated, including all cats presenting with gastrointestinal clinical disorders and had positive parasitological stool sample tests (Faust and Willis techniques) for any type of endoparasite. We evaluated the data obtained from these cats, such as sex, breed, age, diet, street access, history of parasitic diseases and season of the year. From the 1725 cats evaluated during this period, there were a total of 60 positive cases. Among these cats, $60 \%$ were males and $40 \%$ were females. Regarding breeds, $68.3 \%$ were mixed breeds, $21.7 \%$ Persian, $8.3 \%$ Siamese, and $1.7 \%$ Himalayan. The ages ranged from 1-11 years old, with an average age of 2 years and 5 months. However, cats up to 6-months old were the most frequently affected. The highest incidence of parasitized cat was for Giardia sp. (65.0\%), followed by Ancylostoma spp. (40.0\%), Dipylidium caninum and Toxocara cati ( $8.3 \%$ each). It was observed that $65 \%$ of cats presented single infections and $35 \%$ mixed infections. This survey analyzed only positive cases of gastrointestinal endoparasites, so it diverges in some respects from other results in the literature. Asymptomatic cats were not considered, but they may be carriers that eliminate parasites in the environment. However, all intestinal endoparasites isolated in cats in this study represent a potential risk of zoonotic infections, which highlights the importance of this data for the adoption of preventive measures, especially in young male cats, which were the most frequently affected in this study and in others.

(c) 2017 Elsevier Inc. All rights reserved.

\section{Introduction}

The population of domestic cats is growing worldwide, perhaps because they are quite adapted to a modern lifestyle. As cats transitioned from pet to family member, caring for their health became a family worry.

Nowadays, pets have great freedom when living inside houses, allowing the transmission of pathogens to surfaces and rooms accessible to other animals and people that share the environment. Despite the benefits pets provide to people, there is also potential health hazards. ${ }^{2}$

With this close relationship, it is important to raise people's awareness about the zoonotic potential of several endoparasites that can infect their cats. A survey conducted by Langoni et $\mathrm{al}^{3}$ at the city of Botucatu, São Paulo, Brazil, estimated that $78.8 \%$ of the people interviewed had dogs or cats, of which $12.1 \%$ were cat owners. However, $42.4 \%$ of those interviewed did not know what verminosis is, whereas $63.8 \%$ claimed to give antiparasitic drugs to their pets. Therefore, it is evident that there is not among the population an adequate level of knowledge regarding responsible pet ownership, highlighting the importance of the veterinarians' guidance about environmental management, treatment, and monitoring.
The aim of this retrospective study was to evaluate the occurrence of intestinal endoparasites in domestic cats, as well as to profile their management and the parasites most commonly found in cats at the city of Botucatu, São Paulo, Brazil.

\section{Material and Methods}

For this study, we evaluated the medical records of all cats treated at the Small Animal Practice Service at the UNESP Veterinary Hospital, campus Botucatu, São Paulo, Brazil, from January 2011 to September 2015. In this survey, we considered all cats presenting gastrointestinal clinical signs and positive copro-parasitological examinations for any type of endoparasite. We excluded the ones treated empirically for intestinal parasitosis and cats that did not undergo copro-parasitological examinations, most commonly due to lack of interest or financial capabilities by the owners.

We reviewed data such as sex and breed and recorded the corresponding occurrence rates. The age was also recorded and the cats were categorized in four groups based on this criterion: up to 6 months; between 6 months and 1 year; between 1 and 5 years; and over 5 years. We also evaluated food intake, street 
access and history of antiparasitic drug administration. We crossreferenced the occurrence of cases with the current season to verify a possible relationship. The occurrence rates for each gastrointestinal endoparasite found were described, as well as the percentage of cats presenting infection caused by only one parasite (single infection) and more than one parasite (mixed infection).

For the copro-parasitological examinations, the search for endoparasites was carried out following the Willis ${ }^{4}$ method, focusing on sodium chloride flotation to indicate nematode eggs, cysts and protozoan oocysts, and the Faust et $\mathrm{al}^{5}$ method, focusing on the zinc sulphate solution flotation to indicate nematode eggs and Giardia sp. cysts.

\section{Statistical Analysis}

To compare the number of cases in each season of the year, analysis of variance (One Way Anova) was used for independent samples (parametric analysis). Distributions were evaluated by Kolmogorov-Smirnov normality test. It was considered significance level of $5 \%$.

\section{Results}

In the study period, there were 60 diagnoses of endoparasites, either single or mixed infection cases, from a total of 1725 cats evaluated, representing $3.48 \%$ of all treated. There were $3,17,19$, 11 , and 10 diagnoses in 2011, 2012, 2013, 2014, and 2015, respectively, confirmed cases of intestinal endoparasites in cats. Among these 60 cases, $60.0 \%(n=36)$ were males and $40.0 \%(n=$ 24) females, so males were more commonly infected. Regarding breeds, 68.3\% $(n=41)$ were mixed breeds cats, $21.7 \%(n=13)$ Persian, 8.3\% ( $n=5)$ Siamese, and 1.7\% $(n=1)$ Himalayan.

The ages ranged from 1-11 years, with average of 2 years and 5 months, however, cats younger than 6 -months old were the most frequently infected, corresponding to $38.6 \%$ of the cases from this study, followed by the ones in the group of ages between 1 and 5 years old (34.1\%), after that cats over 5 years old (15.9\%), and finally cats with ages between 6 months old and 1 year (11.4\%).

Among the studied cats, 59.0\% were fed only with dry food; $25.0 \%$ had dry food as their main source of nutrition, but also received homemade food (cooked or raw); and $16.0 \%$, mostly kittens, ate other types of food, such as breast milk and baby food. Data regarding water intake was not available for most cats and, therefore, was not included in the study.

Totally, $38 \%$ (40\%) of the cats in this survey had street access and $60 \%$ stayed inside house full time. Among all cats, $63.3 \%$ had been given antiparasitic drugs recently and the remaining $36.7 \%$ had not. Most of owners did not know the anthelmintic they used in their cats, neither its dosage.

The largest number of cases was recorded during Winter (36.7\%), followed by Fall (31.6\%), Summer (16.7\%), and Spring (15.0\%). No significant statistical difference $(P \leq .05)$ was observed regarding seasons, however we observed more cases in Winter.

Considering the period as whole and parasites found both in single and mixed infections, there was a higher incidence of parasitized cats by Giardia sp. in $65.0 \%(n=39)$ of the cats, followed by Ancylostoma spp. in $40.0 \%(n=24)$, and lastly Dipylidium caninum and Toxocara cati, each with $8.3 \%(n=5)$.

Data about ectoparasites control in cats diagnosed with Dipylidium showed that four (80\%) of the cats had fleas, and only an owner of one cat $(20 \%)$ denied fleas presence.

In the survey, we observed that 39 cases (65\%) had only 1 type of intestinal endoparasite, whereas 21 cases (35\%) presented more than 1 endoparasite in the copro-pasitological examination. The
Table

Number ( $n$ ), Percentage (\%), and Type of Associations of Endoparasites Found in Our Study

\begin{tabular}{lcc}
\hline Association & $n$ & $\%$ \\
\hline Ancylostoma spp. + Giardia sp. & 6 & 10.0 \\
Cystoisospora spp. + Giardia sp. & 5 & 8.33 \\
Ancylostoma spp. + Cystoisospora spp. & 4 & 6.67 \\
Ancylostoma spp. + Toxocara cati & 1 & 1.67 \\
Cystoisospora spp. + Toxocara cati & 1 & 1.67 \\
Giardia sp. + Toxocara cati & 1 & 1.67 \\
Ancylostoma spp. + Cystoisospora spp. + Dipylidium caninum & 1 & 1.67 \\
Ancylostoma spp. + Cystoisospora spp. + Giardia sp. & 1 & 1.67 \\
Ancylostoma spp. + Dipylidium caninum + Toxocara cati & 1 & 1.67 \\
Cystoisospora spp. + Giardia sp. + Toxocara cati. & 1 & 1.67 \\
\hline
\end{tabular}

associations that occurred in our study are represented in the Table.

\section{Discussion}

This survey analyzed only cases with positive copro-parasitological examinations for gastrointestinal endoparasites in cats that sought veterinary care. These results diverged from previous studies that showed a higher prevalence of parasitsm.

Likewise, the parasitism by Giardia sp. was the most prevalent in this study, differing from most other studies in the literature, however, it is important to highlight that this study did not consider asymptomatic cats.

In this study, most infected cats were mixed breeds, but it should be noted that most cats attended at the survey location are mixed breeds. The predominant occurrence in young cats observed by this survey is important for veterinarians, who must guide owners or people that wish to adopt a kitten about proper care and preventive measures, as well institute protocols of anthelmintic administration. Comparable results regarding age were described by Riggio et $\mathrm{al}^{6}$ and Lorenzini et $\mathrm{al}^{7}{ }^{7}$ who reported that cats younger than 6-months old were the most frequently infected by intestinal parasites.

Pivoto et $\mathrm{al}^{8}$ also observed comparable results regarding the cats' feeding habits: most of them also received commercially available pet food, which was related to a better nutritional status and immunological capacity. Regarding the seasons, differing results were observed by Lorenzini et $\mathrm{al}^{7}{ }^{7}$ who observed an in number of affected cats during summer, followed by fall, spring and winter.

In a similar survey conducted in the Rio de Janeiro metropolitan area, there was a predominance of parasitism by Ancylostoma spp. (43.5\%) and Giardia sp. was only diagnosed in 6.1\% of cases, ${ }^{9}$ differing from the results observed by this survey. In a study conducted in the city of Maringá, there was a higher prevalence of Giardia sp., corroborating our findings. ${ }^{10}$ However, that study observed an occurrence rate of only $9 \%$, while this study observed a rate of $65 \%$.

According to Stalliviere et $\mathrm{al}^{11}$ at the city of Lages (Santa Catarina, Brazil), $37.8 \%$ of the cats tested were positive for intestinal parasites and those observed most often were Toxocara sp. and Ancylostoma spp., differing from the results observed in our study. In Porto Alegre (Rio Grande do Sul, Brazil), 20.5\% of studied cats presented intestinal parasitism, 5.9\% infected by Toxocara spp., $5.6 \%$ by Isospora and $3.8 \%$ by Ancylostoma, ${ }^{7}$ also differing from our results.

In Hungary, Albania, Italy, Spain, France, Portugal, Belgium, Austria, and Romania, studies have shown a prevalence of Toxocara sp., followed by Ancylostoma spp. and Cystoisospora spp. 
Depending on the studied location. ${ }^{6,12-14}$ As the main parasitosis observed in this study was Giardiasis, these reports present divergent results. Some studies regarding gastrointestinal parasitosis conducted in Europe have shown results similar to those observed in Brazil. In Évora (Portugal) Giardia sp. was most common parasite (13.6\%) in dogs and cats, corroborating our results. However, unlike other studies, many of the cats were from animal shelters, ${ }^{15}$ which may justify these results.

The results observed in this study are in line with those observed by Mircean et $\mathrm{al}^{16}$ and McGlade et $\mathrm{al}^{17}{ }^{17}$ who noted higher rates of parasitized cats by only 1 agent.

It is important to consider that this study considered only positive cases of gastrointestinal endoparasites, which may cause the results to differ from those observed in studies considering randomly selected feline populations. ${ }^{10,11,16}$ In addition, we did not consider animals with complaints of gastrointestinal clinical signs, but with negative copro-parasitological examinations. Similarly, cats without gastrointestinal clinical signs were also not included, and that is an important fact to consider since they may often be carriers and be responsible for eliminating the parasite to the environment. Despite this gap, the results are relevant since all isolated agents have zoonotic potential.

Nowadays, the role of domestic dogs and cats is focused almost exclusively on human-animal interaction. This fact was confirmed by Alves et $\mathrm{al}^{18}{ }^{18}$ who applied a questionnaire to a portion of the population from Uberlândia, Brazil, and observed that $70 \%$ of the people interviewed had a pet and most of them allowed their animals to stay inside the house day and night. The presence of pets in the domestic environment can help in kids in social and physical aspects, and aid in the welfare of people, particularly in the elderly. ${ }^{11}$

Intestinal parasites such as helminths and protozoans are commonly found in domestic animals and the possibility of transmitting diseases from cats to humans is a potential health hazard. ${ }^{15}$ The risk of infections caused by contaminated cat feces plays a key role in the epidemiology of several zoonotic diseases. Methods to raise awareness and promote the prevention and control of such diseases are efficient in reducing environmental contamination with zoonotic parasitic agents.

The most common intestinal parasite observed in this survey was the protozoan Giardia sp. (54.9\%), whose most common infection method is the ingestion of water contaminated with cysts disseminated by infected animals. It may also infect people, so it is considered a zoonosis. ${ }^{19}$ Clinical manifestations are variable from asymptomatic to acute or chronic diarrhea, dehydration, abdominal pain, nausea, vomiting, and weight loss. ${ }^{20}$

The prevalence of giardiasis in humans are generally lower in developed countries, but it can reach $30 \%$ in developing countries. $^{21}$ The life cycle is direct and there are 2 main stages (trophozoite and cyst, the last 1 is the infective one). Contaminated food or water, or by the fecal-oral route can cause the infection. $^{22}$

Animal infections are common, so zoonotic transmission has been widely debated. There are 8 different genotypes recognized, the types A and B, occurring in both humans and animals, are generally considered to be zoonotic. ${ }^{23}$

Therefore, the frequency with which this parasite was detected in this study is a very important piece of information regarding cats in this region, highlighting the importance of orienting owners regarding hygiene and sanitary measures to be adopted in confirmed cases or cases under suspicion.

From a zoonotic point of view, the type of hookworm found (Ancylostoma spp.) is acquired through the ingestion of eggs or through newly hatched larvae that can penetrate the skin. ${ }^{19}$ Cutaneous larva migrans can be diagnosed where there are dogs and cats infected with hookworms and kids are present higher risk of infection when they play in sand tanks. ${ }^{10}$ Therefore, it is important to explain to owners how to properly manage and dispose of, especially in the presence of children.

Among cestodes, the only 1 noted in this study was Dipylidium caninum. Fleas and lice are intermediate hosts and responsible for transmission. ${ }^{19}$ Human infection is also more common in children and happens when they accidentally ingest fleas infected with the parasite. However, the treatment is simple and pathogenicity is low. ${ }^{24}$

The nematode Toxocara cati is often found in cats. ${ }^{19}$ Among the zoonotic diseases, visceral larva migrans stands out. This infection is caused by Toxocara spp. in humans and is considered an emerging zoonosis. ${ }^{7}$ Ocular larva migrans, known in humans as Toxocariasis, occurs more often in children and is caused by accidental ingestion of the parasite's eggs. ${ }^{24}$

Little is known about what practices for parasite control have been applied and how owners apply them in their homes. In addition, level of knowledge of owners regarding parasites and diseases caused by them, as well as measures adopted by pet owners in public places, need to be evaluated to raise awareness regarding these topics. ${ }^{25}$

It is important to highlight once again the importance of providing adequate orientation to owners of cats that are parasite carriers, as well as the need of further population studies involving human and canine species living together with cats carrying intestinal parasites.

\section{Conclusions}

In conclusion, in this study, all gastrointestinal endoparasites found in cats represents potential zoonotic risks. Male cats younger than 6 months old are the main group affected, and it is the veterinarian's duty to advise pet owners regarding hygiene and the regular administration of anthelmintics to avoid spreading diseases.

\section{References}

1. Lyons LA, Kurushima JD. The feline genome and clinical genetics: a short natural history of the cat and its relationship with humans. In: Little. The cat: clinical medicine and management. St. Louis, Mo: Elsevier; 2011. p. 1254

2. Overgaauw PAM, Zutphen LV, Hoek D, et al. Zoonotic parasites in fecal samples and fur from dogs and cats in The Netherlands. Vet Parasitol 163:115-122, 2009

3. Langoni H, Troncarelli MZ, Rodrigues EC, et al. Conhecimento da população de Botucatu-SP sobre guarda responsável de cães e gatos. Vet Zootec 18:297-305, 2011

4. Willis HH. A simple levitation method for the detection of hookworn ova. Med J Aust 8:375-376, 1921

5. Faust EC, D'Antoni J, Odom V, et al. A critical study of clinical laboratory techniques for the diagnosis of protozoan cysts and helminth eggs in feces. Am J Trop Med Hyg 18:169-183, 1938

6. Riggio F, Mannella R, Ariti G, Perrucci S. Intestinal and lung parasites in owned dogs and cats from central Italy. Vet Parasitol 193:78-84, 2013

7. Lorenzini G, Tasca T, De Carli GA. Prevalence of intestinal parasites in dogs and cats under veterinary care in Porto Alegre, Rio Grande do Sul, Brazil. Braz J Vet Res Anim Sci 44:137-145, 2007

8. Pivoto FL, Lopes LFD, Vogel FSF, Botton AS, Sangioni LA. Ocorrência de parasitos gastrointestinais e fatores de risco de parasitismo em gatos domésticos urbanos de Santa Maria, RS, Brasil. Cienc Rural 43:1453-1458, 2013

9. Serra $\mathrm{CMB}$, Uchôa CMA, Coimbra RA. Exame parasitológico de fezes de gatos (Felis catus domesticus) domiciliados e errantes da Região Metropolitana do Rio de Janeiro, Brasil. Ver Soc Bras Med Trop 36:331-334, 2003

10. Pegoraro J, Agostini C, Leonardo JMLO. Incidência de parasitas intestinais de caráter zoonótico em cães e gatos na região de Maringá. In: VII EPCC-Encontro Internacional de Produção Científica Cesumar, Maringá, PR. Anais Eletrônico VII EPCC-Encontro Internacional de Produção Científica Cesumar, CESUMAR-Centro Universitário de Maringá, Editora CESUMAR, Maringá-Paraná-Brasil. Available in: http://www.cesumar.br/prppge/pesquisa/epcc2011/anais/jaqueline_pegoraro1. pdf. 2011.

11. Stalliviere FM, Bellato V, Souza AP, Sartor AA, Moura AB, Rosa LD. Ectoparasitos e helmintos intestinais em Felis catus domesticus da cidade de Lages, SC, Brasil e aspectos socioeconômicos e culturais das famílias dos proprietários dos animais. Rev Bras Parasitol Vet 18:26-31, 2009 
12. Beugnet F, Bourdeau P, Chalvet-Monfray K, Cozma V, Farkas R, Guillot J, et al Parasites of domestic owned cats in Europe: co-infestations and risk factors. Parasit Vectors 7:291-304, 2014

13. Capári B, Hamel D, Visser M, Winter R, Pfister K, Rehbein S. Parasitic infections of domestic cats, Felis catus, in western Hungary. Vet Parasitol 192:33-42, 2013

14. Knaus M, Rapti D, Shukullari E, et al. Characterisation of ecto and endoparasites in domestic cats from Tirana, Albania. Parasitol Res 113:3361-3371, 2014

15. Ferreira FS, Pereira-Baltasar P, Parreira R, et al. Intestinal parasites in dogs and cats from the district of Évora, Portugal. Vet Parasitol 179:242-245, 2011

16. Mircean V, Titilincu A, Vasile C. Prevalence of endoparasites in household cat (Felis catus) populations from Transylvania (Romania) and association with risk factors. Vet Parasitol 171:163-166, 2010

17. McGlade TR, Robertson ID, Eliiot AD, Read A, Thompson RCA. Gastrointestinal parasites of domestic cats in Perth, Western Australia. Vet Parasitol 117: 251-262, 2003

18. Alves TL, Naves AA, Santos TEL, et al. O perfil dos proprietários de animais domésticos na cidade de Uberlândia-MG. RAC-Eletrônica 1(2). Available at: http:/ www.computacao.unitri.edu.br/erac/index.php/e-rac/article/view/93/99. 2012
19. Nelson RW, Couto CG. Medicina Interna de Pequenos Animais. 5th ed. Rio de Janeiro: Elsevier; 2014

20. Cacciò SM, Ryan U. Molecular epidemiology of giardiasis. Mol Biochem Parasitol 160:75-80, 2008

21. Feng Y, Xiao L. Zoonotic potential and molecular epidemiology of Giardia species and giardiasis. Clin Microbiol Rev 24:110-140, 2011

22. Gardner TB, Hill DR. Treatment of giardiasis. Clin Microbiol Rev 14:114-128, 2001

23. Beck R, Sprong H, Pozio E, Cacciò SM. Genotyping Giardia duodenalis isolates from dogs: lessons from a multilocus sequence typing study. Vector Borne Zoonotic Dis 12:206-213, 2012

24. Gennari S.M. Principais helmintos intestinais em cães no Brasil. Boletim Bayer Veterinário 2015. Year n. 2, 8th ed. Available in: https://www.researchgate.net/ publication/279538629. June 2015.

25. Matos M, Alho AM, Owen SP, Nunes T, Carvalho LM. Parasite control pratices and public perception of parasitic diseases: a survey of dog and cat owners. Prev Vet Med 122:174-180, 2015 